\title{
A Cross-Sectional Study on Patient Satisfaction Regarding Teleconsultation Practice During the Covid-19 Pandemic in a Neuro-Psychiatric Hospital in South India
}

\author{
Anjana Rathan"1, Bijulakshmi P. ${ }^{2}$, Mathumathi S. ${ }^{3}$, Vikram Ramasubramanian4, M. Kannan ${ }^{5}$ \\ 1, 2 Department of Psychology, Ahana hospitals LLP, Gandhi Nagar, Madurai, Tamil Nadu, India. \\ 3,4 Department of Psychiatry, Ahana Hospitals LLP, Gandhi Nagar, Madurai, Tamil Nadu, India. ${ }^{5}$ M.S. \\ Chellamuthu Trust and Research Foundation, Madurai, Tamil Nadu, India.
}

\section{ABSTRACT}

\section{BACKGROUND}

Telemedicine involving teleconsultation has been a boon to people during this pandemic situation. Safeguarding one against the infection should not put people who are in dire need of medical help feel helpless and desperate. Teleconsultation, which was previously used for people who did not have access to medical help due to geographical isolation, has come to the rescue of people during this pandemic, and sometimes it is the only timely help that is available to people in need. We wanted to measure the patient satisfaction level regarding the use of telemedicine for psychiatric and psychological consultations during the Covid-19 pandemic.

\section{METHODS}

The level of patient satisfaction was measured using the patient experience and satisfaction survey' proposed (The Research and Development Survey-RANDS) (measuring patient experience and satisfaction to telemedicine, 2020) to measure the level of satisfaction to telemedicine during this pandemic situation, regarding the use of telemedicine for patients who consulted doctors and psychologists in a psychiatric hospital in South India. People who participated filled the questionnaire through google form links sent to them.

\section{RESULTS}

The results indicate that $28 \%$ of people who consulted psychiatrists, recorded scores indicating that they were satisfied with the teleconsultation service, while 71 $\%$ of people who consulted psychologists reported being highly satisfied with the consultation. This study indicated that some still preferred direct interaction with psychiatrists as evidenced by $72 \%$ of people feeling dissatisfied with teleconsultation.

\section{CONCLUSIONS}

This study shows that with people struggling with mental illness direct interaction is crucial in the treatment process, however, teleconsultation could be used for emergencies to ensure compliance with medication and for monitoring symptoms in patients.

\section{KEY WORDS}

COVID 19, Teleconsultation, Neuro-Psychiatric Hospital, Patient Satisfaction
Corresponding Author: Dr Bijulakshmi P., Consultant Psychologist, Ahana hospitals LLP, Gandhi Nagar, Madurai - 625020, India. E-mail: bijuparthiban26@gmail.com

\section{DOI: $10.14260 /$ jemds/2021/586}

How to Cite This Article:

Rathan A, Bijulakshmi P, Mathumathi S, et al. A cross-sectional study on patient satisfaction regarding teleconsultation practice during the covid-19 pandemic in a neuro-psychiatric hospital in South India.J Evolution Med Dent Sci 2021;10(34): 2874-2878, DOI:

10.14260/jemds/2021/586

Submission 09-03-2021,

Peer Review 23-06-2021,

Acceptance 30-06-2021,

Published 23-08-2021.

Copyright (C) 2021 Anjana Rathan et al This is an open access article distributed under Creative Commons Attribution License [Attribution 4.0 International (CC $B Y 4.0)]$ 


\section{BACKGROUND}

The novel coronavirus disease Covid-19 was declared a pandemic ${ }^{1}$ by the world health organization on $11^{\text {th }}$ March 2020. Since then, countries around the world are struggling to control the spread of the virus. The primary method of controlling the spread of infection is imposing lockdown, with special emphasis on social distancing. We have adapted to a new normal of online classes, online payments, and purchases to retain our normal life while keeping ourselves safe. One major hurdle is the accessibility to medical services for Covid related and non-Covid related medical care during this period of lockdown. Medical help which was easily accessible previously has now become difficult. Medical experts have been advised to temporarily suspend nonessential procedures for the safety of both the patient and the doctor. Seeking medical attention in these times has naturally become a challenge. Persons suffering from mental health problems need consistent monitoring and support to ensure that there is no disruption of therapy to prevent relapses and reduce the number of disability-adjusted life years (DALY).

Telemedicine could be defined as "the effective use of communication networks for the delivery of healthcare services". ${ }^{2}$ Studies have shown that telemedicine services have been a boon in conditions where people live in remote regions and hence access to medical services is not possible 3,4 and has been suggested for use in emergency services. ${ }^{5}$ Teleconsultaion has been in practice for many years but medical professionals and the public have been reluctant to try this techno-driven initiative due to various issues such as internet connectivity, poor knowledge in the use of technology among other issues. People believe in the traditional concept of the necessity of contacting medical professionals in real-time. Before this pandemic situation, teleconsultation services were offered only for emergency purposes but this pandemic has made it an essential mode of delivering health care services across all areas of specialities.

This pandemic situation has pushed many healthcare professionals to look to telemedicine for consultations. ${ }^{6}$ Teleconsultation has been preferred by many medical professionals ${ }^{7}$ and there have been many studies suggesting it as a safe, quick method and at an affordable cost ${ }^{8}$ ensuring that people do not need to travel thus reducing the risk of transmission of Covid-19.

People with mental health conditions need consistent medical and psychological help and this pandemic induced lockdown has been stressful for them. Teleconsultation helps people to create their own therapeutic space inside one's living room and talk to the psychologist and a psychiatrist on a smartphone, computer screen, or any other device that offers secure internet and video capabilities. In this time of social distancing, it is the perfect solution to improve mental health without having to put physical health in danger. Stress about contracting the infection, change in economic status, and loss of loved ones due to the illness among other factors have all increased the prevalence of anxiety and depression among people and teleconsultation acts as a boon to people during this stressful situation. With pandemics causing sudden infection waves, the unpredictability of the situation is bound to affect people adversely. The importance of psychological first aid has never been more essential than in recent years.
Studies have shown that people have benefitted from teleconsultation during the Covid-19 pandemic.9,10 While studies are analyzing the clinical benefits of teleconsultations, no studies are analyzing the benefits of teleconsultations from the perspective of the patients who used the service during this pandemic situation. Patient feedback is crucial since this is a novel mode of consultation to many, and feedback helps in making the transition patient-friendly and beneficial. It helps to improve upon the mode of teleconsultation services as this pandemic situation is predicted to persist for months to come.

This study intended to measure the level of satisfaction about the use of teleconsultation, among people who sought psychological help with psychiatrists and psychologists, during the Covid-19 pandemic.

\section{METHODS}

This study was approved by the Institutional Ethics committee. This is a cross-sectional study conducted online from April $2^{\text {nd }}$ to May $3^{\text {rd }}, 2020$ in a neuro-psychiatric hospital. The study was conducted based on the questions related to teleconsultation services for the patients who sought help during the Covid-19 crisis. Patients underwent an online survey through google forms after their first teleconsultation. The survey consisted of statements regarding basic socio-demographic details and a questionnaire; 'The patient experience and satisfaction survey' to measure the patients' level of satisfaction in using teleconsultation. The participants provided informed consent before taking part in this survey.

We used the "The patient experience and satisfaction survey' proposed (The Research and Development SurveyRANDS $)^{11}$ to measure the level of satisfaction to telemedicine during this pandemic situation. The research and development survey (RANDS) is a platform designed for conducting survey question evaluation and statistical research. RANDS is an ongoing series of a survey from probability-sampled commercial survey panels used for methodological research at the National Centre for Health Statistics (NCHS). The patient experience and satisfaction survey using a 4-point Likert scale measures the level of satisfaction on using telemedicine in various domains such as easy accessibility, ease of using and perceived usefulness and effectiveness. Higher scores indicate higher levels of satisfaction, and lower scores indicate a lower level of satisfaction.

The hospital issued a helpline number on social media. Messages were sent to patients with the caption "Online consultation is now available" with phone numbers. All the employees in the hospital circulated the messages to their friends and family about the availability of teleconsultation. 338 calls were recorded from new and previously visited patients, in which 144 calls requested psychiatric consultations and were connected to psychiatrists, and the rest of the 194 calls were connected only to the psychologists. An online survey form was sent to the patients after their first consultation via SMS and WhatsApp to fill about their experiences in teleconsultation. 330 persons responded of 
whom, 8 responses were excluded because they were incomplete, and 322 responses were analysed.

\section{Statistical Analysis}

Data generated from the questionnaire were analysed using Statistical software (SPSS version 16). Data were analysed in terms of frequency percentages, mean and standard deviation. Qualitative data obtained from the respondents during the interview were also utilized to get the complete picture of the teleconsultation process and its challenges.

\section{RESULTS}

The socio-demographic details of the participants as indicated in Table 1 were found to be normally distributed. The average age of the respondents was 45.2, with the minimum age of the respondents at $21 \mathrm{yrs}$. and the maximum age at 69 yrs. The mean score of the total score obtained in the patient satisfaction survey was 32.39 .

\begin{tabular}{|c|c|c|c|c|}
\hline & & N (\%) & Mean & Std. Deviation \\
\hline \multirow{3}{*}{ Total * Gender } & Male & $184(57.1 \%)$ & 32.33 & 8.326 \\
\hline & Female & $138(42.9 \%)$ & 32.47 & 8.177 \\
\hline & Total & $322(100 \%)$ & 32.39 & 8.250 \\
\hline \multirow{6}{*}{ Total * Education } & & $\mathrm{N}(\%)$ & Mean & Std. Deviation \\
\hline & Primary & $62(19.3 \%)$ & 34.45 & 6.613 \\
\hline & secondary & $43(13.4 \%)$ & 30.81 & 10.128 \\
\hline & UG & $190(59.0 \%)$ & 32.36 & 8.178 \\
\hline & PG & $27(8.4 \%)$ & 30.41 & 8.219 \\
\hline & Total & $322(100 \%)$ & 32.39 & 8.250 \\
\hline \multirow{5}{*}{$\begin{array}{l}\text { Total }{ }^{*} \text { Economic } \\
\text { status }\end{array}$} & & $\mathrm{N}(\%)$ & Mean & Std. Deviation \\
\hline & High & $20(6.2 \%)$ & 33.65 & 7.909 \\
\hline & Middle & $262(81.4 \%)$ & 32.52 & 8.169 \\
\hline & Low & $40(12.4 \% 0$ & 30.90 & 8.944 \\
\hline & Total & $322(100 \%)$ & 32.39 & 8.250 \\
\hline \multirow{4}{*}{$\begin{array}{c}\text { Total } * \text { new patient } \\
\text { / old patient }\end{array}$} & & $\mathrm{N}(\%)$ & Mean & Std. Deviation \\
\hline & New & $198(61.5 \%)$ & 32.05 & 8.381 \\
\hline & Old & $124(38.5 \%)$ & 32.94 & 8.040 \\
\hline & Total & $322(100 \%)$ & 32.39 & 8.250 \\
\hline \multirow{4}{*}{$\begin{array}{c}\text { Total * Psychiatrist } \\
\text { / Psychologist }\end{array}$} & & $\mathrm{N}(\%)$ & Mean & Std. Deviation \\
\hline & Doctor & $139(43.2 \%)$ & 24.97 & 7.553 \\
\hline & Psychologist & $183(56.8 \%)$ & 38.03 & 1.675 \\
\hline & Total & $322(100 \%)$ & 32.39 & 8.250 \\
\hline
\end{tabular}

When the various statements included in the survey regarding the persons who had sought psychiatric or psychological help, were compared with the mean total scores obtained in the patient satisfaction survey, it can be seen that there was no significant difference in the total score when gender, education or by the fact the person was an old or new client. But there was a significant difference in the mean scores of persons who had consulted psychiatrists $(\mathrm{M}=$ $24.97, \mathrm{SD}=7.55)$ and who had consulted psychologists $(\mathrm{M}=$ 38.03, $\mathrm{SD}=1.67$ ).

When the individual responses to the statements in the survey were analysed (figure 1), it was found that nearly 64 $\%$ of the individuals agreed to the statements indicating satisfaction with the consultation while $36 \%$ of the individuals disagreed with the statements indicating dissatisfaction.

Responses to statements regarding patient satisfaction indicate that only $28 \%$ (25\% and $3 \%$ ) who had consulted psychiatrists responded positively (strongly agreed, agreed) to statements in the survey, while $72 \%$ responded negatively to statements regarding dissatisfaction with their consultations (figure 2).

This was in contrast to patients who consulted psychologists through teleconsultation, with $71 \%$ (57 \% and $14 \%)$ of people who consulted psychologists agreed with most statements in the survey indicating that they were satisfied with the consultation (figure 3) and only $29 \%$ disagreed to the statements in the survey.

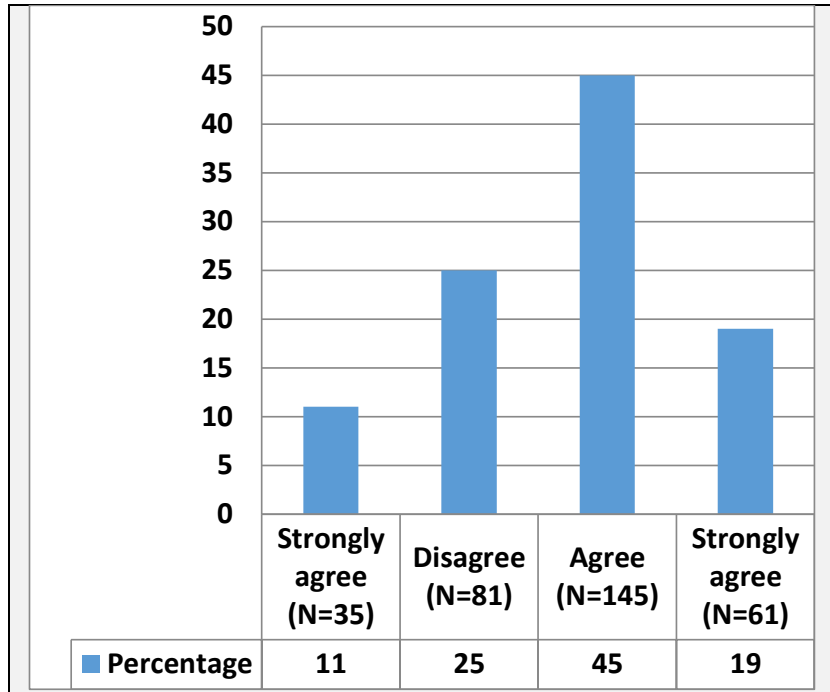

Figure 1. Overall Percentage of Responses to the Individual Statements
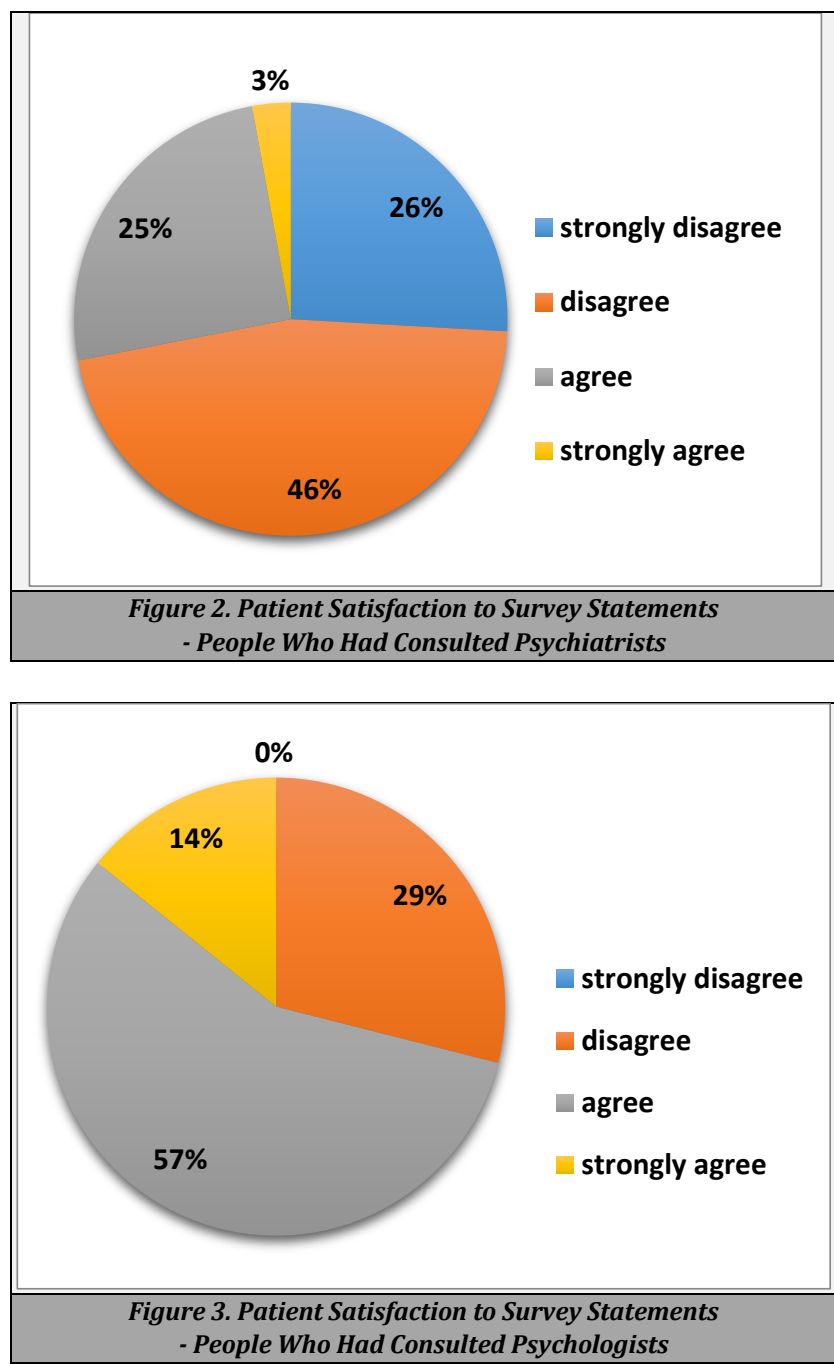


\section{DISCUSSION}

This study involving patient's satisfaction towards teleconsultation has shown that most people were satisfied with the consultation with doctors and psychologists. This result is similar to a study in India ${ }^{12}$ regarding feedback towards teleconsultation in 2016, which reported nearly 90 $\%$ of the patients being highly satisfied with the service. Telemedicine in India has proven to be a boon by helping doctors monitor patients remotely and helps connect specialists to patients in remote regions. ${ }^{13}$ Globally, the use of teleconsultation services has risen during this Covid-19 situation as shown by systemic reviews ${ }^{14}$ with most people reporting to be highly satisfied. However, a study in India ${ }^{15}$ during Covid-19 shows that only $53 \%$ of people were willing to use teleconsultation. The Covid-19 situation has pushed clinicians toward teleconsultation particularly in the care of people suffering from mental illness.

This sudden shift could account for people feeling odd consulting doctors over the phone, but they were thankful for being able to connect to psychiatrists. Persons suffering from mental illness need personalized care and patients reported missing face to face contact with their doctors as clearly indicated by the results.

However, it should be noted that as with the previous studies when consulting with psychologists, ${ }^{16}$ patients were satisfied with the care provided, as evidenced by the scores. Teleconsultation has ensured that mental health services are not interrupted for patients during the Covid-19 pandemic in a safe environment. People in home isolation and those who have recovered from the illness require psychological help during this pandemic situation and teleconsultation has been a boon for seeking relief from distress. Teleconsultation has also ensured that people who were already suffering from psychiatric illness had no disruption in their regular consultation with their therapists and the doctors. People seeking psychological help have all been grateful for being able to consult with counsellors during this pandemic period. Teleconsulting has ensured that people had access to a safe space to discuss their issues. Persons who had consulted doctors through teleconsultation.

The advancement in telecommunication services has ensured that people are not deprived of mental health services during the Covid-19 situation. The world health organization has recommended that mental health services be improved to cater to the needs of the people during this crisis. Teleconsultation is a boon to make mental health services accessible to all during the Covid-19 pandemic.

\section{CONCLUSIONS}

In conclusion, we found that the quality of mental health professional and patient communication, as indicated by information exchange, interpersonal relationship building, and shared decision making, did not differ between online and face-to-face consultations. But when consulting psychiatrists, patients preferred to have direct consultation, since they feel more comfortable when they see a doctor faceto-face. As this study shows that the interaction quality and satisfaction level are independent of the consultation medium in psychologists, these results may hopefully offer a step forward in this process.

Future studies can be done on how to increase the efficacy and quality of teleconsultation through video consultation. A major drawback would be connectivity issues in telecommunication services and lack of privacy during the consultation, for people living in close-knit family systems.

Data sharing statement provided by the authors is available with the full text of this article at jemds.com.

Financial or other competing interests: None.

Disclosure forms provided by the authors are available with the full text of this article at jemds.com.

\section{REFERENCES}

[1] World Health Organization. Coronavirus disease (COVID19) pandemic. Health Emergencies 2021. https://www.euro.who.int/en/health-topics/healthemergencies/coronavirus-covid-19

[2] Sood S, Mbarika V, Jugoo S, et al. What is telemedicine? A collection of 104 peer-reviewed perspectives and theoretical underpinnings. Telemed J E Health 2007;13(5):573-90.

[3] Mars M. Telemedicine and advances in urban and rural healthcare delivery in Africa. Prog Cardiovasc Dis 2013;56(3):326-35.

[4] Anker SD, Koehler F, Abraham WT. Telemedicine and remote management of patients with heart failure. Lancet 2011;378(9792):731-9.

[5] Craig J, Patterson V. Introduction to the practice of telemedicine. J Telemed Telecare 2005;11(1):3-9.

[6] Hollander JE, Carr BG. Virtually perfect? Telemedicine for covid-19. N Engl J Med 2020;382(18):1679-81.

[7] Portnoy J, Waller M, Elliott T. Telemedicine in the Era of COVID-19. J Allergy Clin Immunol Pract 2020;8(5):148991.

[8] Calton B, Abedini N, Fratkin M. Telemedicine in the time of coronavirus. J Pain Symptom Manage 2020;60(1):e124.

[9] Colle R, El Kader Ait Tayeb A, De Larminat D, et al. Shortterm acceptability by patients and psychiatrists of the turn to psychiatric teleconsultation in the context of the COVID-19 pandemic. Psychiatry Clin Neurosci 2020;74(8):443-4.

[10] Bocher R, Jansen C, Gayet P, et al. Responsiveness and sustainability of psychiatric care in France during COVID-19 epidemic. Encephale 2020;46(3S):S81-4.

[11] Measuring patient experience and satisfaction to telemedicine. Center for Care Innovations 2020 [cited 2020 Aug 20]. https://www.careinnovations.org/wpcontent/uploads/Patient-Experience-and-Satisfactionwith-Telemedicine.pdf

[12] Acharya R, Rai J. Evaluation of patient and doctor perception toward the use of telemedicine in Apollo Tele Health Services, India. J Fam Med Prim Care 2016;5(4):798-803.

[13] Chellaiyan VG, Nirupama AY, Taneja N. Telemedicine in India: where do we stand? J Fam Med Prim Care 2019;8(6):1872-6. 
[14] Andrews E, Berghofer K, Long J, et al. Satisfaction with the use of telehealth during COVID-19: an integrative review. Int J Nurs Stud Adv 2020;2:100008.

[15] Singh A, Tyagi N, Purwar N, et al. A cross sectional study to assess the impact of telemedicine on health care services in primary health centre, North India. Asian J
Med Princ Clin Pract 2020;3(1):1-8.

[16] Dorstyn DS, Saniotis A, Sobhanian F. A systematic review of telecounselling and its effectiveness in managing depression amongst minority ethnic communities. J Telemed Telecare 2013;19(6):338-46. 